\title{
Atypical small acinar proliferation and two or more cores of high-grade intraepithelial neoplasia on a previous prostate biopsy are significant predictors of cancer during a transperineal template-guided saturation biopsy aimed at sampling one core for each I $\mathrm{mL}$ of prostate volume
}

This article was published in the following Dove Press journal:

Research and Reports in Urology

21 September 2017

Number of times this article has been viewed

Yasushi Nakai'

Nobumichi Tanaka'

Makito Miyake'

Shunta Hori'

Yoshihiro Tatsumi ${ }^{1,2}$

Yosuke Morizawa'

Tomomi Fujii ${ }^{2}$

Noboru Konishi

Kiyohide Fujimoto'

'Department of Urology, Nara Medical University, ${ }^{2}$ Department of Pathology, Nara Medical University, Kashihara-shi, Nara, Japan
Correspondence: Nobumichi Tanaka Department of Urology, Nara Medical University, 840 Shijo-cho, Kashihara-shi, Nara, Japan 634-8522

$\mathrm{Tel}+8 \mid 74422305$ I

Fax +8I 744257657

Email sendo@naramed-u.ac.jp
Objective: The objective of this study was to evaluate whether high-grade prostatic intraepithelial neoplasia (HGPIN) and atypical small acinar proliferation (ASAP) predict prostate cancer (PCa) during repeat transperineal template saturation biopsy with a high number of cores per prostate volume in patients with persistent clinical suspicion of $\mathrm{PCa}$ who underwent at least one previous negative transrectal ultrasound (TRUS)-guided biopsy.

Methods: We retrospectively evaluated 135 consecutive patients with persistent clinical suspicion of $\mathrm{PCa}$, despite a set of negative TRUS-guided biopsies and increasing prostate-specific antigen levels; abnormal findings on digital rectal examination, TRUS, or magnetic resonance imaging; previous biopsy showing HGPIN; and previous biopsy showing atypical glands. Transperineal template saturation biopsy (TTSB) was performed at $5 \mathrm{~mm}$ intervals to sample one core for each $1 \mathrm{~mL}$ of prostate volume.

Results: The median rate of biopsy cores per prostate volume was 1.00 (range: $0.75-1.39$ ). The PCa detection rates in patients who were diagnosed with HGPIN, or had two or more cores of HGPIN or ASAP, were 53\% (9/17), 89\% (8/9), and 83\% (10/12), respectively. Two or more HGPIN cores and ASAP were positive predictors of PCa on TTSB. The high-grade cancer rates (Gleason score $[\mathrm{GS}] \geq 7$ ) in patients with ASAP and two or more cores of HGPIN were $20 \%$ and $80 \%$, respectively. The cancer detection rate represented by a GS score $\geq 8$ in patients with ASAP or two or more cores of HGPIN at a previous TRUS-guided biopsy was $5.5 \%(1 / 18)$.

Conclusion: ASAP or two or more cores of HGPIN at a previous TRUS-guided biopsy strongly indicated the presence of PCa on TTSB.

Keywords: atypical small acinar proliferation, high-grade intraepithelial neoplasia, transperineal template-guided saturation biopsy, prostate cancer, repeat biopsy

\section{Introduction}

Prostate-specific antigen (PSA) testing has been widely used for prostate cancer (PCa) screening, and transrectal ultrasound (TRUS)-guided biopsies have been widely performed. ${ }^{1,2}$ However, even with the contemporary use of laterally directed extended TRUS-guided biopsies, the false-negative rate remains high. ${ }^{3}$ Patients whose condition was diagnosed as negative with a TRUS-guided biopsy have been considered for a 
repeat biopsy if the following findings are present: increased PSA levels; abnormal findings on digital rectal examination (DRE), TRUS, and magnetic resonance imaging (MRI); and a previous biopsy showing high-grade prostatic intraepithelial neoplasia (HGPIN) and/or atypical small acinar proliferation (ASAP).

HGPIN is defined as proliferation of the acini and ducts in epithelial cells, similar to $\mathrm{PCa} .{ }^{4}$ The presence of HGPIN seen on sextant biopsy has been considered a strong predictor of PCa at repeat biopsy $\left(45 \% 0^{5}\right.$ and $\left.35 \% \%^{6}\right)$. With octant biopsy, the rate of carcinoma seen on repeat biopsy for patients with HGPIN has decreased $\left(19.9 \%{ }^{7}\right.$ and $\left.12.6 \%{ }^{8}\right)$. Merrimen et al reported that multifocal HGPIN was a significant risk factor for PCa in 12,304 men. ${ }^{9}$ Roscigno et al showed that the presence of two or more cores of HGPIN was a significant predictive factor for $\mathrm{PCa}$ at repeat saturation biopsy. ${ }^{10}$

ASAP reflects a broad group of lesions of varying clinical significance, including lesions that mimic cancer and many lesions that demonstrate retrospectively focal carcinoma but contain insufficient cytological or architectural atypia to establish a definitive diagnosis of cancer. ${ }^{11}$ Previous studies suggested that, on average, 30\%-40\% (range: $17 \%-70 \%$ ) of patients with ASAP harbor adenocarcinoma at a subsequent prostate biopsy. ${ }^{12,13}$ Accordingly, current American ${ }^{14}$ and European ${ }^{15}$ guidelines recommend immediate repeat biopsy within 3-6 months after an initial diagnosis of ASAP.

HGPIN (extended or two or more cores) and ASAP have been recognized as potential risk factors for PCa. However, the clinical meaning of HGPIN and ASAP seen on repeat saturation biopsy has not been adequately reported. Furthermore, Patel et $\mathrm{al}^{16}$ and Leone et $\mathrm{al}^{17}$ reported that cancer detected on repeat biopsy after a diagnosis of ASAP and HGPIN is rarely found to be high-grade cancer. Therefore, there is not enough evidence to support the use of saturation biopsy for HGPIN and ASAP. In a previous study, we conducted a saturation biopsy that required one biopsy core per milliliter of prostate volume,${ }^{18}$ and we showed that there was a high mean number of biopsy cores per unit prostate volume of 1.06 core $/ \mathrm{mL}$. With this method, we can obtain a sufficient sample and precise diagnosis. Therefore, in this study, we evaluated whether the presence of HGPIN and ASAP at a previous biopsy is a positive predictor of $\mathrm{PCa}$ during transperineal template saturation biopsy (TTSB) and sought to determine the results of patients who have the findings of HGPIN and ASAP.

\section{Patients and methods}

\section{Patient selection}

Between January 2006 and January 2015, 967 patients received a TRUS-guided biopsy in our hospital due to the suspicion of PCa. A TRUS-guided biopsy was performed according to the procedure of our previous report. ${ }^{2}$ The condition of 432 patients $(44.7 \%)$ was diagnosed as negative. Among these patients, $23(2.3 \%)$ and 17 (1.6\%) patients were diagnosed with HGPIN and ASAP, respectively. We recommended a repeat biopsy for all patients with HGPIN and ASAP. Consequently, 18 and 12 patients with HGPIN and ASAP, respectively, underwent a repeat saturation biopsy. Patients with HGPIN were included in the HGPIN diagnostic category. Patients with ASAP alone or ASAP with HGPIN were included in the ASAP diagnostic category. ${ }^{9}$

Between July 2006 and August 2015, we offered TTSB to patients who were considered to need a repeat prostate biopsy when the following clinical factors were present: increased PSA levels; abnormal findings on DRE, TRUS, or MRI; and a previous biopsy that showed HGPIN and/or ASAP. The number of TRUS-guided biopsies at TTSB was 1-5 negative biopsies (median: 1 ), and the median time from the last TRUS-guided biopsy to TTSB was 651 days (range, 84-3,522). A total of 135 consecutive patients who received repeated TTSB were enrolled in this study. Then, we retrospectively analyzed the data. Two genitourinary pathologists established all pathologic diagnoses. The institutional review board of Nara Medical University approved this study.

\section{TTSB procedure}

We previously reported on the TTSB method that we used in this study. ${ }^{18}$ A transrectal probe (Toshiba Medical, Tochigi, Japan) that was attached to a brachytherapy stepping unit (AccuSeed, Bedfordshire, UK) was inserted into the rectum. The low-echoic area was estimated, and the prostate volume was calculated by using the following formula: length $\times$ width $\times$ height $\times 0.5236$. The space between biopsy cores in a row was uniformly $5 \mathrm{~mm}$ from right to left in the longitudinal view, except for the area nearest to and around the urethra. When a sufficient sample was not taken from the apex of the bladder because of large prostate volume, we considered using an additional core to take the sample from a point near the bladder. To achieve "saturation biopsy," one biopsy core per milliliter of prostate volume was required. The biopsy was performed by using an 18-gauge, 25-cm-long biopsy gun (Bard, Covington, GA, USA). 
For patients with multiple PSA measurements prior to the saturation biopsy, we used the most recent value before the saturation biopsy date. Insignificant cancer was defined as a clinically insignificant Gleason score (GS) of 6, maximum tumor length of $<4.5 \mathrm{~mm}$, and total tumor length of $<5.5 \mathrm{~mm}$ based on a report by Epstein et al. ${ }^{19}$

\section{Statistical analysis}

The statistical analysis was performed with SPSS for Windows (version 20.0; IBM, Armonk, NY, USA). Mann-Whitney $U$ test was used for continuous variables, and chi-square test was used for categorical variables. A binary logistic regression analysis was used to estimate the independent parameters of positive TTSB. The cutoff value was determined as the point closest to the upper lefthand corner of the receiver operating characteristic curve. A univariate analysis was applied to isolate variables with a significant value of $P<0.05$. Variables that were found to predict $\mathrm{PCa}$ in the univariate analysis were included in the multivariate analysis. A $P$ value $<0.05$ was considered statistically significant.

\section{Results}

\section{Patient characteristics}

The patients' characteristics are summarized in Table 1. The numbers of cores obtained from the last TRUS-guided biopsies in the HGPIN $(P=0.004)$ and ASAP groups $(P=0.04)$ were significantly higher than those in the benign group. The PSA levels of the HGPIN $(P=0.003)$ and ASAP $(P=0.04)$ groups were significantly lower than those of the benign group. The PSA velocity in the HGPIN group $(P=0.02)$ was significantly lower than that of the benign group. No patient had ASAP and HGPIN simultaneously.

\section{TTSB results}

The median number of cores that were taken with TTSB was 37 (range: 16-75), and the median number of biopsy cores per prostate volume was 1.00 (range: $0.75-1.39$ ). The detection rate of PCa with TTSB was $48.1 \%$ (65/135 patients). Eight patients $(5.9 \%)$ developed urinary retention after TTSB, and every patient was free from catheterization within 1 month after TTSB. No patient experienced a urinary tract infection (Table 2). The detection rate of PCa in patients who had been

Table I Patients' clinical and pathological features

\begin{tabular}{|c|c|c|c|c|c|}
\hline & \multicolumn{5}{|c|}{$\begin{array}{l}\text { Diagnosis on previous biopsy } \\
\text { Median (range) or } \mathbf{n}(\%)\end{array}$} \\
\hline & $\begin{array}{l}\text { Benign } \\
n=105 \text { (range) }\end{array}$ & $\begin{array}{l}\text { ASAP } \\
n=12 \text { (range) }\end{array}$ & $P$-value & $\begin{array}{l}\text { HGPIN } \\
n=18 \text { (range) }\end{array}$ & $P$-value \\
\hline Age, years & $\begin{array}{l}70 \\
(47-83)\end{array}$ & $\begin{array}{l}63 \\
(48-74)\end{array}$ & $0.06 * *$ & $\begin{array}{l}70 \\
(37-75)\end{array}$ & $0.67 * *$ \\
\hline No. of previous TRUS biopsies & $\begin{array}{l}1 \\
(1-5)\end{array}$ & $\begin{array}{l}1 \\
(1-4)\end{array}$ & $0.98 * *$ & $\begin{array}{l}1 \\
(I-2)\end{array}$ & $0.53 * *$ \\
\hline No. of cores obtained from the last TRUS-guided biopsy & $\begin{array}{l}10 \\
(8-13)\end{array}$ & $\begin{array}{l}12 \\
(8-12)\end{array}$ & $0.04 * *$ & $\begin{array}{l}12 \\
(8-13)\end{array}$ & $0.004 * *$ \\
\hline Time from the last TRUS-guided biopsy to TTSB, days & $\begin{array}{l}651 \\
(84-3522)\end{array}$ & $\begin{array}{l}534 \\
(69-2332)\end{array}$ & $0.19 * *$ & $\begin{array}{l}515 \\
(57-1263)\end{array}$ & $0.42 * *$ \\
\hline PSA, ng/mL & $\begin{array}{l}9.7 \\
(1.9-107)\end{array}$ & $\begin{array}{l}7.1 \\
(4.2-17.5)\end{array}$ & $0.04 * *$ & $\begin{array}{l}7.0 \\
(4.5-36.7)\end{array}$ & $0.003 * *$ \\
\hline PSA density, $\mathrm{ng} / \mathrm{mL} / \mathrm{mL}$ & $\begin{array}{l}0.26 \\
(0.06-1.9)\end{array}$ & $\begin{array}{l}0.19 \\
(0.13-0.58)\end{array}$ & $0.50 * *$ & $\begin{array}{l}0.17 \\
(0.08-0.57)\end{array}$ & $0.47^{* *}$ \\
\hline PSA velocity, $\mathrm{ng} / \mathrm{mL} /$ year & $\begin{array}{l}1.2 \\
(-29-182)\end{array}$ & $\begin{array}{l}0.89 \\
(-2.4-3.2)\end{array}$ & $0.35 * *$ & $\begin{array}{l}0.36 \\
(-29-25)\end{array}$ & $0.02 * *$ \\
\hline DRE, abnormal findings & $\begin{array}{l}17 \\
(16.1)\end{array}$ & $\begin{array}{l}3 \\
(25.0)\end{array}$ & $0.39 *$ & $\begin{array}{l}3 \\
(16.7)\end{array}$ & $0.89 *$ \\
\hline TRUS, abnormal findings & $\begin{array}{l}23 \\
(21.9)\end{array}$ & $\begin{array}{l}2 \\
(16.7)\end{array}$ & $0.72 *$ & $\begin{array}{l}3 \\
(16.7)\end{array}$ & $0.66 *$ \\
\hline Prostate volume, $\mathrm{mL}$ & $\begin{array}{l}38.7 \\
(18-76.7)\end{array}$ & $\begin{array}{l}30.5 \\
(20-57)\end{array}$ & $0.10 * *$ & $\begin{array}{l}46 \\
(25-65)\end{array}$ & $0.48 * *$ \\
\hline Two or more cores HGPIN on the last biopsy & - & - & & $\begin{array}{l}9 \\
(50.0)\end{array}$ & \\
\hline No. of cores obtained from TTSB & $\begin{array}{l}36 \\
(16-75)\end{array}$ & $\begin{array}{l}33 \\
(18-62)\end{array}$ & $0.33^{* *}$ & $\begin{array}{l}41 \\
(23-54)\end{array}$ & $0.51 * *$ \\
\hline
\end{tabular}

Notes: $*$ Chi-square test, $* *$ Mann-Whitney $U$ test.

Abbreviations: ASAP, atypical small acinar proliferation; HGPIN, high-grade prostatic intraepithelial neoplasia; TRUS, transrectal ultrasound; TTSB, transperineal template saturation biopsy; PSA, prostate-specific antigen; DRE, digital rectal examination. 
diagnosed with HGPIN was 53\% (9/17) and that in patients who had been diagnosed with HGPIN with two or more cores was $89 \%(8 / 9)$. The detection rate of $\mathrm{PCa}$ in patients who had been diagnosed with ASAP was 83\% (10/12).

Table 2 TTSB results

\begin{tabular}{ll}
\hline & Median (range) or $\mathbf{n}(\%)$ \\
\hline No. of cores on TTSB & $37(16-75)$ \\
Core/volume, cores/mL & $1.00(0.75-1.39)$ \\
Urinary tract infection & $0(0)$ \\
Retention & $8(5.9)$ \\
No. of patients with positive cores & $65(48.1)$ \\
\hline
\end{tabular}

Abbreviation: TTSB, transperineal template saturation biopsy.

\section{Analysis of factors that predict PCa on TTSB}

In the multivariate analysis, the factors that predicted $\mathrm{PCa}$ on TTSB were high age (odds ratio [OR]: 3.99, 95\% confidence interval [CI]: 1.55-10.3), high PSA density (OR: 6.89, 95\% CI: 2.62-18.2), low prostate volume (OR: 0.24 , 95\% CI: 0.09-0.63), two or more cores of HGPIN on the last biopsy (OR: 22.9, 95\% CI: 2.27-230), and the findings of ASAP at the last biopsy (OR 14.7, 95\% CI 2.35-91.6). Repeated TTSB significantly identified PCa in patients diagnosed with two or more cores of HGPIN and ASAP but not in patients diagnosed benign on previous TRUS-guided biopsy (Table 3 ).

Table 3 Univariate and multivariate analyses of factors that positively predict prostate cancer

\begin{tabular}{|c|c|c|c|c|}
\hline Variables/Categories & $\begin{array}{l}\text { Univariate analysis } \\
\text { OR }(95 \% \mathrm{Cl})\end{array}$ & $P$-value & $\begin{array}{l}\text { Multivariate analysis } \\
\text { OR }(95 \% \mathrm{Cl})\end{array}$ & $P$-value \\
\hline \multicolumn{5}{|l|}{ Age (years) } \\
\hline$\leq 70.1$ & (Ref) & & (Ref) & \\
\hline$>70.1$ & $3.50(1.71-7.16)$ & $<0.01$ & $3.99(1.55-10.3)$ & 0.004 \\
\hline \multicolumn{5}{|l|}{ No. of TRUSB } \\
\hline$=\mathrm{I}$ & $($ Ref) & & & \\
\hline$>1$ & $0.87(0.37-2.07)$ & 0.76 & & \\
\hline \multicolumn{5}{|c|}{ No. cores obtained by last TRUS-guided biopsy } \\
\hline$\leq 10$ & $($ Ref) & & & \\
\hline$>10$ & $1.38(0.68-2.79)$ & 0.37 & & \\
\hline \multicolumn{5}{|l|}{ PSA (ng/mL) } \\
\hline$\leq 10.9$ & (Ref) & & & \\
\hline$>10.9$ & $1.91(0.95-3.84)$ & 0.07 & & \\
\hline \multicolumn{5}{|l|}{ PSA density (ng/mL/mL) } \\
\hline$\leq 0.28$ & $($ Ref) & & (Ref) & \\
\hline$>0.28$ & $5.2(2.45-11.0)$ & $<0.01$ & $6.89(2.62-18.2)$ & $<0.001$ \\
\hline \multicolumn{5}{|l|}{ PSA velosity (ng/mL/year) } \\
\hline$\leq 1.2$ & (Ref) & & & \\
\hline$>1.2$ & $1.91(0.95-3.81)$ & 0.07 & & \\
\hline \multicolumn{5}{|l|}{ DRE } \\
\hline Benign & (Ref) & & & \\
\hline Suspicious & $2.20(0.86-5.62)$ & 0.09 & & \\
\hline \multicolumn{5}{|l|}{ TRUS } \\
\hline Benign & (Ref) & & (Ref) & \\
\hline Suspicious & $2.72(1.12-6.58)$ & 0.03 & $1.57(0.45-4.82)$ & 0.53 \\
\hline \multicolumn{5}{|l|}{ Prostate volume $(\mathrm{mL})$} \\
\hline$\leq 34.1$ & (Ref) & & (Ref) & \\
\hline$>34.1$ & $0.21(0.09-0.43)$ & $<0.01$ & $0.24(0.09-0.63)$ & 0.004 \\
\hline \multicolumn{5}{|l|}{ HGPIN on the last biopsy } \\
\hline Benign & (Ref) & & & \\
\hline Present & $1.47(0.55-3.92)$ & 0.43 & & \\
\hline \multicolumn{5}{|c|}{ Two or more cores HGPIN on the last biopsy } \\
\hline Benign & (Ref) & & (Ref) & \\
\hline Present & $9.08(1.10-74.7)$ & 0.04 & $22.9(2.27-230)$ & 0.008 \\
\hline \multicolumn{5}{|l|}{ ASAP on the last biopsy } \\
\hline Benign & (Ref) & & (Ref) & \\
\hline Present & $5.78(1.21-27.5)$ & 0.03 & $14.7(2.35-91.6)$ & 0.004 \\
\hline
\end{tabular}

Abbreviations: ASAP, atypical small acinar proliferation; HGPIN, high-grade prostatic intraepithelial neoplasia; TRUS, transrectal ultrasound; TRUSB, transrectal ultrasoundguided biopsy; TTSB, transperineal template saturation biopsy; PSA, prostate-specific antigen; DRE, digital rectal examination. 


\section{Pathological features of patients who were diagnosed with $\mathrm{PCa}$}

In the patient group whose condition was diagnosed as benign on previous TRUS-guided biopsies, the numbers of patients with $1,2-5,6-9$, and 10 or more positive cores were 11/45 (24\%), 20/45 (44\%), 8/45 (18\%), and 6/45 (13\%), respectively. The numbers of patients with a GS of $6,7,8$, and 9 were $11 / 45$ (24\%), 26/45 (58\%), 5/45 (11\%), and 3/45 (7\%), respectively. The rate of significant cancer was $84 \%(38 / 45$ patients) (Table 4).

In the patient group with two or more cores of HGPIN at the last TRUS-guided biopsies, the numbers of patients with $1,2-5,6-9$, and 10 or more positive cores were $3 / 8$ (38\%), 4/8 (50\%), 1/8 (12\%), and 0/8 (0\%), respectively. The numbers of patients with a GS of $6,7,8$, and 9 were $6 / 8$ (75\%), $1 / 8(13 \%), 0 / 8(0 \%)$, and $1 / 8(13 \%)$, respectively. The rate of significant cancer was $63 \%$ (5/8 patients) (Table 4$)$.

In the patient group with ASAP at the last TRUS-guided biopsies, the numbers of patients with $1,2-5,6-9$, and 10 or more positive cores were $3 / 10(30 \%), 5 / 10(50 \%), 2 / 10$ $(20 \%)$, and $0 / 10(0 \%)$, respectively. The numbers of patients with a GS of $6,7,8$, and 9 were $2 / 10(20 \%), 8 / 10(80 \%)$, $0 / 10(0 \%)$, and $0 / 10(0 \%)$, respectively. The rate of significant cancer was $80 \%$ (8/10 patients) (Table 4$)$.

Table 4 The number of positive cores and cancer grade

\begin{tabular}{|c|c|c|c|}
\hline \multirow[b]{3}{*}{$\begin{array}{l}N=126 \\
n(\%) \text { or median (range) }\end{array}$} & \multicolumn{3}{|c|}{ Findings at a previous biopsy } \\
\hline & Benign & ASAP & $\begin{array}{l}\text { HGPIN } \\
\text { (two or } \\
\text { more cores) }\end{array}$ \\
\hline & $N=105$ & $N=12$ & $\mathbf{N}=9$ \\
\hline Positive on TTSB & $45(43)$ & $10(83)$ & $8(89)$ \\
\hline No. of positive cores & & $P=0.66^{*}$ & $P=0.60^{*}$ \\
\hline 1 & II (24) & $3(30)$ & $3(38)$ \\
\hline $2-5$ & $20(44)$ & $5(50)$ & $4(50)$ \\
\hline $6-9$ & $8(18)$ & $2(20)$ & $I(I 2)$ \\
\hline$\geq 10$ & $6(13)$ & 0 & 0 \\
\hline Gleason score & & $P=0.49 *$ & $P=0.02 *$ \\
\hline 6 & II (24) & $2(20)$ & $6(75)$ \\
\hline 7 & $26(58)$ & $8(80)$ & I (I3) \\
\hline 8 & $5(I I)$ & 0 & 0 \\
\hline 9 & $3(7)$ & 0 & $\mathrm{I}(13)$ \\
\hline \multirow[t]{2}{*}{ Maximum tumor length $(\mathrm{mm})$} & & $P=0.06 * *$ & $P=0.36 * *$ \\
\hline & $9(I-20)$ & $4(I-10)$ & $7(I-\mid 4)$ \\
\hline \multirow[t]{2}{*}{ Total tumor length (mm) } & & $P=0.17^{* *}$ & $P=0.37 * *$ \\
\hline & $20(I-I 70)$ & $8(2-23)$ & $16(1-14)$ \\
\hline \multirow[t]{2}{*}{ Significant cancer } & & $P=0.75^{*}$ & $P=0.09 *$ \\
\hline & $38(84)$ & $8(80)$ & $5(63)$ \\
\hline
\end{tabular}

Notes: *Chi-square test; **Mann-Whitney $U$ test.

Abbreviations: HGPIN, high-grade prostatic intraepithelial neoplasia; ASAP, atypical small acinar proliferation; TTSB, transperineal template saturation biopsy.
The GS in patients whose condition was diagnosed as benign on previous TRUS-guided biopsies was significantly higher $(P=0.02)$ than that of patients with two or more cores of HGPIN. The proportion of significant cancer was not significantly lower $(P=0.09)$ in patients with two or more cores of HGPIN than in those with a benign diagnosis on previous TRUS-guided biopsies. The GS $(P=0.49)$ or the proportion of significant cancer $(P=0.75)$ in patients with a benign diagnosis on previous TRUS-guided biopsies was not significantly different from that of patients who were diagnosed with ASAP on previous TRUS-guided biopsies (Table 4).

\section{Discussion}

In this study, we evaluated whether HGPIN and ASAP at a previous biopsy were positive predictors of PCa on TTSB that was aimed at sampling one core for each $1 \mathrm{~mL}$ of prostate volume. We found that two or more cores of HGPIN at a previous TRUS-guided biopsy were positive predictors of PCa. Recently, some reports have shown that extensive HGPIN was a significant predictive factor of $\mathrm{PCa}$ at repeat biopsy, comparable to the results of our study.,10,23 Based on these facts, two or more cores of HGPIN on a TRUSguided biopsy with 10 or 12 cores strongly indicate the presence of $\mathrm{PCa}$. Furthermore, the detection rate $(88.9 \%)$ of $\mathrm{PCa}$ at repeat biopsy in patients who had two or more cores of HGPIN at a previous TRUS-guided biopsy is higher than those of other reports $\left(30.9 \%,{ }^{20} 31.8 \%,{ }^{21}\right.$ and $40 \%{ }^{10}$ ). The high detection rate of $\mathrm{PCa}$ in the present study can be explained as follows. The first reason is selection bias, because all patients who were diagnosed as having ASAP or HGPIN at a previous TRUS-guided biopsy did not undergo TTSB. Second, we used a longer period (515 days) between the previous TRUS-guided biopsy and TTSB than that of other reports $\left(153^{21}, 228^{20}\right.$, and $294^{10}$ days). Lefkowitz et $\mathrm{al}^{22}$ found that patients with HGPIN on the initial extended biopsy had a $2.3 \%$ incidence of cancer at 1 year on repeat extended biopsy and a rate of $25.8 \%$ at 3 years. Based on these results, the long period between the previous TRUS biopsy and TTSB in the present study may have increased the rate of $\mathrm{PCa}$. The third reason is the higher number of biopsy cores per unit of prostate volume in the present study. The median number of biopsy cores per unit of prostate volume was one core $/ 1 \mathrm{~mL}$. This number is the highest among all reports about TTSB. ${ }^{18}$ Lee et a ${ }^{20}$ reported that a high number of cores predicts $\mathrm{PCa}$ in patients who were diagnosed with HGPIN at a previous biopsy. These facts may contribute to the high detection rate of $\mathrm{PCa}$ in 
patients who had two or more cores of HGPIN at a previous TRUS-guided biopsy.

Some reports indicate that $\mathrm{PCa}$ in patients with HGPIN on previous TRUS-guided biopsy is insignificant. ${ }^{16,17}$ Patel et al ${ }^{16}$ reported that $98 \%$ of patients with HGPIN at the initial biopsy demonstrated GS of either $3+3(86 \%)$ or $3+4(12 \%)$. In the present study, the rate of PCa (GS of 6, 7, and 8) in patients with HGPIN at a previous TRUS biopsy was $37.5 \%, 75 \%$, and $12.5 \%$, respectively, and the rate was significantly lower in these patients than in benign patients who underwent a previous TRUS-guided biopsy. This result is comparable with that of previous reports. ${ }^{16,17}$ Based on these results, patients with HGPIN seen on a previous TRUS-guided biopsy preceding a diagnosis of PCa usually show favorable pathology, even with saturation biopsy.

The detection rate of $\mathrm{PCa}$ on repeat saturation biopsy in patients with ASAP who underwent a previous biopsy ranges between $35.4 \%$ and $61.3 \%$, and the presence of ASAP on previous TRUS-guided biopsies is a significant, positive predictor of $\mathrm{PCa}$ on a saturation biopsy. ${ }^{23-25}$ In addition, in the present study, the frequency of diagnosing PCa was $83 \%$, and the presence of ASAP at a previous biopsy was a significant, positive predictor of PCa on TTSB aimed at sampling one core for each $1 \mathrm{~mL}$ of prostate volume. This result is comparable with previous reports and shows that the findings of ASAP on prostate biopsy strongly indicate the presence of $\mathrm{PCa}$. The detection rate of $\mathrm{PCa}$ in the present study was higher than those of other reports. ${ }^{23-25}$ The reasons for the high positive rate in the present study are the same as those previously stated (selection bias, long time between previous TRUS-guided biopsy and TTSB, and the number of biopsy cores).

Leone et al reported that $69 / 89$ (78\%) patients who were diagnosed with PCa with the findings of ASAP at a previous biopsy had a GS of $3+3$ or less, 15/89 (17\%) had a GS of 7 , and $6 / 89(6 \%)$ had a GS $\geq 8-10 .{ }^{17}$ Chen et al reported that $11.8 \%$ of patients with ASAP at previous biopsies had a GS of 7 or greater. ${ }^{26}$ In the present study, the detection rates of significant PCa and GS of 6 and 7 in patients with ASAP at a previous TRUS-guided biopsy were $80 \%, 20 \%$, and $80 \%$, respectively, and the detection rate of significant cancer and each GS was not significantly lower than that in benign patients who underwent previous TRUS-guided biopsy. The detection rate of significant cancer and GS in the present study were higher than those in other studies. Furthermore, five patients $(50 \%)$ had a GS of $4+3$ in the present study. Although these discrepancies are difficult to explain, the small population and selection bias for TTSB may be the reason for a high rate of significant cancer and high GS.
The present study has several limitations. First, this was a retrospective study. Second, all patients who were diagnosed with HGPIN or ASAP with TRUS biopsy did not undergo TTSB. Although we offered TTSB to all patients who were considered to need a repeat prostate biopsy with a previous biopsy showing HGPIN and/or ASAP, 10 patients did not receive TTSB because they refused to undergo the procedure. Furthermore, the median time between the previous TRUSguided biopsy and TTSB was much longer than 6 months. Most patients did not undergo TTSB within 6 months after a preTRUS biopsy due to their own choice, although American ${ }^{14}$ and European $^{15}$ guidelines recommend immediate repeat biopsy within 3-6 months after an initial diagnosis of ASAP. The last limitation was the small number of patients who underwent radical prostatectomy. Although seven patients who were diagnosed with $\mathrm{PCa}$ underwent radical prostatectomy, and the GS for specimens from prostatectomy were accordant with the GS for TTSB, the number is very small. In future, comparing the results of TTSB with those of prostatectomy is needed to evaluate whether TTSB aimed at sampling one core for each $1 \mathrm{~mL}$ of prostate volume can precisely evaluate $\mathrm{PCa}$.

\section{Conclusion}

The findings of ASAP or two or more cores of HGPIN at a previous TRUS-guided biopsy strongly indicate the presence of PCa on TTSB with a high number of biopsy cores per unit of prostate volume.

\section{Ethics approval and consent to participate}

The institutional review board (IRB) of the Nara Medical University approved this study. As the data for the study were obtained through retrospective chart review, a waiver of informed consent was approved by the IRB. Personal information linked to research subjects and donors was anonymized (when necessary, the information was labeled with an identifying code to make it possible to distinguish between the individuals). Then, de-identified patient data were analyzed.

\section{Disclosure}

The authors report no conflicts of interest in this work.

\section{References}

1. Barry MJ. Clinical practice. Prostate-specific-antigen testing for early diagnosis of prostate cancer. N Engl J Med. 2001;344:1373-1377.

2. Tanaka N, Shimada K, Nakagawa Y, et al. The optimal number of initial prostate biopsy cores in daily practice: a prospective study using the Nara Urological Research and Treatment Group nomogram. BMC Res Notes. 2015;8:689. 
3. Kawakami S, Okuno T, Yonese J, et al. Optimal sampling sites for repeat prostate biopsy: a recursive partitioning analysis of three-dimensional 26-core systemic biopsy. Eur Urol. 2007;51:675-683.

4. Bostwick DG, Amin MB, Dundore P, Marsh W, Schultz DS. Architectural patterns of high-grade prostatic intraepithelial neoplasia. Hum Pathol. 1993;24:298-310.

5. Aboseif S, Shinohara K, Weidner N, et al. The significance of prostatic intra-epithelial neoplasia. Br J Urol. 1995;76:355-359.

6. Davidson D, Bostwick DG, Qian J, et al. Prostatic intraepithelial neoplasia is a risk factor for adenocarcinoma: predictive accuracy in needle biopsies. J Urol. 1995;154:1295-1299.

7. Postma R, Roobol M, Schröder FH, van der Kwast TH. Lesions predictive for prostate cancer in a screened population: first and second screening round findings. Prostate. 2004;61:260-266.

8. San Francisco IF, Olumi AF, Kao J, Rosen S, DeWolf WC. Clinical management of prostatic intraepithelial neoplasia as diagnosed by extended needle biopsies. BJU Int. 2003;91:350-354.

9. Merrimen JL, Jones G, Walker D, Leung CS, Kapusta LR, Srigley JR. Multifocal high grade prostatic intraepithelial neoplasia is a significant risk factor for prostatic adenocarcinoma. J Urol. 2009;182: 485-490.

10. Roscigno M, Scattoni V, Freschi M, et al. Diagnosis of isolated highgrade prostatic intra-epithelial neoplasia: proposal of a nomogram for the prediction of cancer detection at saturation re-biopsy. BJU Int. 2012;109:1329-1334.

11, Epstein JI, Herawi M. Prostate needle biopsies containing prostatic intraepithelial neoplasia or atypical foci suspicious for carcinoma: implications for patient care. J Urol. 2006;175:820-834.

12. Borboroglu PG, Sur RL, Roberts JL, et al. Repeat biopsy strategy in patients with atypical small acinar proliferation or high grade prostatic intraepithelial neoplasia on initial prostate needle biopsy. J Urol. 2001;166:866-870.

13. Scattoni V, Roscigno M, Freschi M, et al. Atypical small acinar proliferation (ASAP) on extended prostatic biopsies: predictive factors of cancer detection on repeat biopsies. Arch Ital Urol Androl. 2005;77:31-36.

14. Carroll PR, Parsons JK, Andriole G, et al. Prostate cancer early detection, version 1.2014. Featured updates to the NCCN Guidelines. J Natl Compr Canc Netw. 2014;12:1211-1219.
15. Heidenreich A, Bastian PJ, Bellmunt J, et al. EAU guidelines on prostate cancer. Part 1: screening, diagnosis, and local treatment with curative intent-update 2013. Eur Urol. 2014;65:124-137.

16. Patel P, Nayak JG, Biljetina Z. Prostate cancer after initial high-grade prostatic intraepithelial neoplasia and benign prostate biopsy. Can $J$ Urol. 2015;22:8056-8062.

17. Leone A, Gershman B, Rotker K, et al. Atypical small acinar proliferation (ASAP): is a repeat biopsy necessary ASAP? A multi-institutional review. Prostate Cancer Prostatic Dis. 2016;19:68-71.

18. Nakai Y, Tanaka N, Anai S, et al. Transperineal template-guided saturation biopsy aimed at sampling one core for each milliliter of prostate volume: 103 cases requiring repeat prostate biopsy. BMC Urol. 2017;17:28.

19. Epstein JI, Sanderson H, Carter HB. Utility of saturation biopsy to predict insignificant cancer at radical prostatectomy. Urology. 2005;66: 356-360.

20. Lee MC, Moussa AS, Zaytoun O, et al. Using saturation biopsy scheme increase cancer detection during repeat biopsy in men with high grade prostatic intra-epithelial neoplasia. Urology. 2011;78:1115-1119.

21. Antonelli A, Tardanico R, Giovanessi L, et al. Predicting prostate cancer at rebiopsies in patients with high-grade prostatic intraepithelial neoplasia: a study on 546 patients. Prostate Cancer Prostatic Dis. 2011;12:173-176.

22. Lefkowitz GK, Taneja SS, Brown J, Melamed J, Lepor H. Followup interval prostate biopsy 3 years after diagnosis of high grade prostatic intraepithelial neoplasia is associated with high likelihood of prostate cancer, independent of change in prostate specific antigen levels. J Urol. 2002;168:1415-1418.

23. Novara G, Boscolo-Berto R, Lamon C, et al. Detection rate and factors predictive the presence of prostate cancer in patients undergoing ultrasonography-guided transperineal saturation biopsies of the prostate. BJU Int. 2010;105:1242-1246.

24. Ahyai SA, Isbarn H, Karakiewicz PI, et al. The presence of prostate cancer on saturation biopsy can be accurately predicted. BJU Int. 2010;105:636-641.

25. Martorana E, Micali S, Ghaith A, et al. Advantages of single-puncture transperineal saturation biopsy of prostate: analysis of outcome in 125 patients using our scheme. Int Urol Nephrol. 2015;47:735-741.

26. Chen YB, Pierorazio PM, Epstein JI. Initial atypical diagnosis with carcinoma on subsequent prostate needle biopsy: findings at radical prostatectomy. J Urol. 2010;184:1953-1957.
Research and Reports in Urology

\section{Publish your work in this journal}

Research and Reports in Urology is an international, peer-reviewed, open access journal publishing original research, reports, editorials, reviews and commentaries on all aspects of adult and pediatric urology in the clinic and laboratory including the following topics: Pathology, pathophysiology of urological disease; Investigation and treatment of

\section{Dovepress}

urological disease; Pharmacology of drugs used for the treatment of urological disease. The manuscript management system is completely online and includes a very quick and fair peer-review system, which is all easy to use. Visit http://www.dovepress.com/testimonials.php to read real quotes from published authors. 